\title{
Thematic Issue on HYDRUS Software Applications to Subsurface Fluid Flow and Contaminant Transport
}

\author{
Jiří Šimůnek ${ }^{1 *}$, Martinus Th. van Genuchten ${ }^{2,3}$, Radka Kodešová ${ }^{4}$ \\ ${ }^{1}$ Department of Environmental Sciences, University of California, Riverside, CA, USA. \\ ${ }^{2}$ Center for Environmental Studies, CEA, São Paulo State University, UNESP, Rio Claro, SP, Brazil. \\ ${ }^{3}$ Department of Earth Sciences, Utrecht University, Netherlands. \\ ${ }^{4}$ Department of Soil Science and Soil Protection, Czech University of Life Sciences, Prague, Czech Republic. \\ *Corresponding author. E-mail: Jiri.Simunek@ucr.edu
}

\section{INTRODUCTION}

This thematic issue documents selected presentations given at the Fifth International Conference on "HYDRUS Software Applications to Subsurface Flow and Contaminant Transport Problems," held in Prague, Czech Republic, March 30-31, 2017, as well as several other papers by authors who did not attend the conference. Previous conferences in the HYDRUS series were held in Utrecht in 2005, in Tokyo in 2008, and in Prague in 2008 and 2013. The conferences focused on the development and application of advanced numerical models simulating fluid flow, heat transport, and/or the transport of various contaminants or other solutes (such as nutrients, pesticides, heavy metals, radionuclides, and pathogenic microorganisms) in variably-saturated soils and groundwater. The conferences were designed to bring together users of the HYDRUS family of codes, as well as of related software, to review and exchange information on various aspects of the codes, future enhancements of the software, and their application to a broad range of soil, environmental, hydrological, ecological, and agricultural problems.

Since the first conference in 2005 , the community of HYDRUS users has been growing continuously as evidenced by the number of downloads (over 10,000 times each of the past several years) and visits to the HYDRUS web pages (several hundred on average each day). Hundreds of journal articles have been published in which the HYDRUS codes have been used (see the review by Šimůnek et al., 2016). Feedback from users such as those attending the HYDRUS conferences has been extremely important in terms of identifying particular strengths and weaknesses of the codes, defining additional processes or features that should be included in the models, or identifying key challenges and new perspectives in modeling a multitude of interacting soil physical, chemical, and biological processes (Vereecken et al., 2016).

Although the HYDRUS codes are now widely used for modeling biogeochemical processes in the vadose zone, a large number of alternative subsurface flow and transport models can be used for similar applications. Popular existing codes (such as MODFLOW-SURFACT, STOMP, SWAP, VS2DI, and TOUGH2) are discussed in detail in a special 2008 issue "Vadose Zone Modeling" of Vadose Zone Journal (Šimůnek and Bradford, 2008), while a more extensive inventory of available models is provided in the Encyclopedia of Hydrological Sciences (Šimůnek, 2005). Steefel et al. (2015) further provided a review of more comprehensive reactive transport codes for subsurface environmental simulations. We refer readers to these additional resources for more information about alternative subsurface flow and transport models.

\section{HYDRUS DEVELOPMENT AND APPLICATIONS}

This special issue contains 12 contributions from HYDRUS software users, covering a range of topics from the very fundamental to important practical applications. The leading paper by Šimůnek et al. (this issue) describes new features that will be available in Version 3 of the HYDRUS (2D/3D) computer software package. Several important new features have been implemented recently in the standard computational module of Version 3. The most important additions relate to root growth and the use of a reservoir boundary condition. While HYDRUS-1D allowed users to prescribe a time-variable rooting depth, using either the logistic growth function or some tabulated form upon input, HYDRUS (2D/3D) thus far assumed that the spatial distribution of roots in the root zone remained constant during the simulations. Šimůnek et al. (this issue) discuss multiple adaptations to overcome this shortcoming. Also, earlier versions of HYDRUS (2D/3D) required pressure heads at boundaries representing external water bodies, such as pumping wells or agricultural furrows, to be specified as an external input, without any feedback that would relate possible changes in their water level in response to flow processes within the subsurface (such as infiltration or exfiltration). The upcoming new HYDRUS version has now an option to account for such interactions using a new reservoir boundary condition. The new root growth and reservoir boundary features were requested by many HYDRUS users; they should undoubtedly extend the applicability of the code to a much broader range of applications. Additionally, the GUI of HYDRUS (2D/3D) has been completely rewritten to ensure compatibility with new Windows operating systems and the development of more efficient software in the near future (Šimůnek et al., this issue). Multiple new tools, such as Manipulator, Clipper, and Slicer, as well as the use of 3D streamlines, were developed for Version 3 of HYDRUS (2D/3D) and are discussed briefly by the authors.

The remaining papers in the thematic issue can be divided into two groups. The first group of papers uses existing standard HYDRUS modules and describes their application to a wide range of problems. Applications range from evaluations of a) the effects of temporal averaging of meteorological data on predictions of groundwater recharge (Batalha et al., this issue), b) flow in capillary barriers (Berger, this issue), c) the Hyprop evaporation method for estimating the unsaturated soil hydraulic properties (Bezerra Coelho et al., this issue), d) the effects of soil water repellency on the unsaturated soil hydraulic properties (Filipović et al., this issue), e) the impact of stones in actual field soils of the High Tatras mountains in Slovakia on soil water storage and recharge (Hlaváčiková et al., this issue), f) how changes in cropping patterns at a large scale can produce 
water savings and social gains (Karimov et al., this issue), to g) ${ }^{137}$ Cs transport from the Goiânia Radioactive Waste Repository in Brazil towards groundwater (Pontedeiro et al., this issue). These applications quite nicely demonstrate the breadth of possible applications of the HYDRUS software packages.

The second group of papers focuses either on applications of existing special add-on modules of HYDRUS, such as HPx for multicomponent contaminant transport (Jacques et al., this issue) and the Wetland module (Pucher and Langergraber, this issue), or on coupling the HYDRUS code with DSSAT (Shelia et al., this issue) or the SWI2 package of MODFLOW (Szymkiewicz et al., this issue). DSSAT is a suite of field-scale, process-based crop models that simulate the phenological development of crops to obtain detailed information about various yield components from emergence till maturity on the basis of crop genetic properties, environmental conditions (soil, weather) and management options (Jones et al., 2003). MODFLOW is the U.S. Geological Survey (USGS) modular finitedifference flow model (McDonald and Harbaugh, 2003), which is considered to be the de facto standard code for simulating groundwater flow. The SWI2 package for MODFLOW may be used to represent in a simplified way variable-density flow associated with saltwater intrusion in coastal aquifers (Bakker et al., 2013).

\section{Applications of the standard HYDRUS modules}

The first paper of this first group of papers discusses the effects of temporal averaging of meteorological data on predictions of groundwater recharge. Batalha et al. (this issue) used HYDRUS-1D to show that temporal averaging of meteorological data can lead to significant bias in predictions of groundwater recharge. They found that an increase in the duration of the averaging interval of meteorological data (from hourly, daily, weekly, monthly to yearly time periods) will lead to lower estimates of groundwater recharge, especially at sites having coarse-textured soils. At one of the study sites in Brazil, daily averaged data produced recharge rates almost ten times greater than those obtained using yearly averaged data (Batalha et al., this issue). This same problem was also studied, with similar conclusions, by Szymkiewicz et al. (this issue) using the HYDRUS package for MODFLOW.

Berger (this issue) used the two-dimensional version of HYDRUS (2D/3D) to evaluate experimental data collected at a 10-m tipping trough representing capillary barriers. Capillary barriers are two-layered systems consisting of an upper layer made up of relatively fine-grained porous material (the capillary layer) underlain by a lower layer consisting of relatively coarse-grained porous material (the capillary block). Water percolating through the capillary layer under unsaturated conditions is then held above the interface between the two layers due to capillary forces and the large difference in their soil hydraulic conductivities. While HYDRUS described flow through the capillary layer and the capillary block relatively well, the software failed to reproduce an abrupt change in the flow pattern that was observed experimentally when increasing rainfall. Instead, the model produced a relatively smooth pattern without any distinct thresholds. Berger (this issue) discusses in detail possible causes for this mismatch, including experimental issues, the application of the model, or the model itself.

An application of HYDRUS-1D to the HYPROP evaporation method for estimating the unsaturated soil hydraulic properties is discussed by Bezerra Coelho et al. (this issue). While earlier applications of HYDRUS-1D using the evaporation method appeared many years ago (e.g., Schelle et al., 2010;
Schindler et al., 2010; Šimůnek et al., 1998), Bezerra Coelho et al. (this issue) provide a much more complete analysis of the method. They used HYDRUS-1D to carry out an independent analysis of the HYPROP system, which standardized the evaporation method, for a broad range of soil textures. The authors conclude that overall, the HYPROP methodology performed extremely well for most soil textures and as such constitutes a much-needed addition to current soil hydraulic measurement techniques (Bezerra Coelho et al., this issue).

An important factor affecting the hydraulic behavior of many soils that is projected to increase in importance due to global climate change is soil water repellency. This feature is rarely modeled successfully using numerical models based on the standard Richards equation (e.g., Deurer and Bachmann, 2007; Diamantopoulos et al., 2013; Robinson et al., 2010). Filipović et al. (this issue) use HYDRUS (2D/3D) to estimate the hydraulic properties of soils exhibiting water repellency using experimental data collected with a disc infiltrometer, and with water and ethanol as the infiltration liquid. They then used the calibrated model to assess the water balance of a hillslope containing soils exhibiting different degrees of water repellency.

Another important factor that affects subsurface water flow, especially in mountainous areas, is the presence of stones that could dramatically constrain the soil volume through which water moves. While stony soils have been studied in the past using HYDRUS (2D/3D) (e.g., Hlaváčiková et al., 2016; Novák et al., 2011; Parajuli et al., 2017), those studies considered only hypothetical soil systems with simplified geometries and idealized distributions of stones. Hlaváčiková et al. (this issue) in this issue used HYDRUS-1D to assess the impact of stones in real soils of the High Tatras mountains in Slovakia on soil water storage and recharge. Their studies indicate that the presence of rock fragments in a moderate-to-high stony soil can significantly decrease the soil water storage (by some $25 \%$ or more) and affect the soil water dynamics.

Karimov et al. (this issue) used HYDRUS-1D to assess how changes in the large-scale cropping patterns of the Fergana Valley in Central Asia can produce water savings and social gains. They examined possible water savings by replacing alfalfa with winter wheat (with either a fallow period or the cultivation of green gram during the summer) for various irrigation scenarios such as high-deficit versus low-deficit irrigation. Karimov et al. (this issue) discussed not only various hydrological components (e.g., transpiration, evaporation, and recharge), but also the many economic and social gains that could be obtained with different cropping scenarios within a relatively broad developmental context.

Finally, Pontedeiro et al. (this issue) used HYDRUS-1D to reassess the Goiânia Radioactive Waste Repository in Brazil stemming from an accident in 1987 with an abandoned cesium chloride teletherapy source. They first obtained estimates of water infiltrating through the soil cover on top of the repository into and through the waste and its concrete liners and the underlying vadose zone towards groundwater. Interestingly, calculations accounted not only for hydrological fluxes resulting from local precipitation and evapotranspiration, including root water uptake by the grass cover, but also for the effects of concrete degradation on the hydraulic properties of the liners. Next, ${ }^{137} \mathrm{Cs}$ transport from the repository towards groundwater was considered while accounting for the effects of ${ }^{137}$ Cs sorption and radioactive decay. Results indicated that very little if any radioactive material would reach the water table during the approximately 400-year lifespan of the repository, even when accounting for preferential flow through the waste using a dualporosity (mobile-immobile water) contaminant transport model. 


\section{Development and applications of HYDRUS add-on modules}

A large number of standard and non-standard add-on modules have been developed over the years to expand the applicability of the HYDRUS software packages. As summarized by Šimůnek et al. (2016) these modules include, but are not limited to, a) the UnsatChem module that simulates the transport and reactions of major ions, b) the HPx modules that consider various general biogeochemical reactions in soils, c) the C-Ride module that simulates the colloid-facilitated solute transport, d) the Wetland module that considers various biogeochemical reactions in constructed wetlands, e) the DualPerm module for simulations of nonequilibrium and/or preferential flow and transport, f) the Fumigant module that considers the fate and transport of fumigants, and g) the Isotope module to simulate the fate and transport of isotopes. The current thematic issue contains two manuscripts describing applications of two of these modules, notably the HPx module (Jacques et al. this issue) and the Wetland module (Pucher and Langergraber, this issue). Additionally, two manuscripts describe the coupling of HYDRUS-1D with DSSAT (Shelia et al., this issue) and MODFLOW (Szymkiewicz et al., this issue).

Jacques et al. (this issue) describe recent developments and applications of the HPx modules for multicomponent reactive transport during variably-saturated flow. The HPx modules are a result of coupling the HYDRUS computational codes with PHREEQC (Parkhurst and Appelo, 2013). They may be used to simulate one- and multi-dimensional water flow and solute transport, in conjunction with a large number of biogeochemical reactions, in variably-saturated soils and other porous systems. Jacques et al. (this issue) gave an overview of the most significant recent developments of HPx, such as the coupling of hydraulic properties with geochemical state variables (e.g., porosity and hydraulic conductivity), considering gaseous diffusion, and facilitating transport in two and three dimensions. They provide multiple examples demonstrating the use of HPx to simulate a range of processes relevant to soil organic matter dynamics in soils, the fate of dissolved organic matter and $\mathrm{CO}_{2}$ transport in soils, as well as bioturbation processes.

Pucher and Langergraber (this issue) analyzed four vertical flow wetland systems using the Wetland module of HYDRUS $(2 \mathrm{D} / 3 \mathrm{D})$. The Wetland module (Langergraber and Šimůnek, 2012) was developed in order to simulate governing biological and chemical transformation and degradation processes of wastewater constituents in subsurface flow treatment wetlands. Pucher and Langergraber (this issue) evaluated whether the default values of various biological and chemical parameters provided by the Wetland module can be used to represent collected experimental data. Their results indicate that for vertical flow wetlands with fine sand, no adjustments of the standard parameter set were needed, while for systems with coarser filter media as the main layer, the standard parameter set had to be adjusted to match simulated and measured effluent concentrations.

The HYDRUS codes previously have been coupled with several crop and/or root growth models as reviewed by Šimůnek et al. (this issue) and Hartmann et al. (2018). Shelia et al. (this issue) report another recent development, i.e., the implementation of HYDRUS flow routines into the DSSAT crop modeling system. DSSAT refers to a suite of field-scale, process-based crop models that simulate the phenological development of crops, including detailed information about various yield components, from emergence till maturity on the basis of crop genetic properties, environmental conditions (soil, weather) and management options (Jones et al., 2003). While the
DSSAT system thus far relied on the "tipping bucket" water balance approach to represent soil hydrologic and water redistribution processes, implementation of the HYDRUS flow routines into DSSAT allows one to use now the more processbased Richards equation to represent these processes. The advantages and disadvantages of the two approaches are well known and have been discussed elsewhere (e.g., Scanlon et al., 2002). Shelia et al. (this issue) provide details about the coupling of the two models, as well as applications of the two approaches to multiple datasets involving not only measured water contents, but also multiple crop growth variables.

The last paper of this thematic issue (Szymkiewicz et al., this issue) discusses the simultaneous use of the HYDRUS and SWI2 packages for MODFLOW to simulate freshwater lens recharge and the position of the salt/freshwater interface. The study was applied to a sandy peninsula, a typical geomorphologic setting in many coastal areas such as along the Baltic and North Sea coasts. The MODFLOW groundwater flow model comes with a large number of "packages" to account for various processes, such as recharge from the vadose zone, and interactions with rivers and ponds. The HYDRUS package for MODFLOW is one such package that considers processes in the vadose zone (Beegum et al., 2018; Twarakavi et al., 2008). The SWI2 package is another package, which may be used to represent in a simplified way variable-density flow associated with saltwater intrusion in coastal aquifers (Bakker et al., 2013). Szymkiewicz et al. (this issue) used both packages simultaneously to highlight the sensitivity of calculated recharge rates to the temporal resolution of weather data (similarly as Batalha et al., this issue), leading to different trends in the evolution of freshwater-saltwater interfaces. They also found that root water uptake can significantly influence both the recharge rate and the position of the freshwater-saltwater interface.

\section{CONCLUSIONS}

The twelve papers in this thematic issue reflect the considerable depth and breadth of possible applications of the HYDRUS software packages and their specialized add-on modules. The thematic issue also indicates continuous improvement of the codes themselves and their GUI's, including the development of new features such as more flexible root growth options and a dynamic reservoir boundary condition, as well as coupling of the HYDRUS codes with separate crop growth models (e.g., DSSAT), biogeochemical models (e.g., PHREEQC), or larger-scale flow and transport models (e.g., MODFLOW). These improvements keep enhancing in minor and major ways the applicability of the HYDRUS family of codes to existing or new applications, and to new areas of research. They provide important additions to the many standard and non-standard add-on HYDRUS modules discussed in detail by Šimůnek et al. (2016).

\section{REFERENCES}

Bakker, M., Schaars, F., Hughes, J.D., Langevin, C.D., Dausman, A.M., 2013. Documentation of the Seawater Intrusion (SWI2) Package for MODFLOW. US Geological Survey Techniques and Methods, Book 6, Chap. A46, 47 p.

Beegum, S., Šimůnek, J., Szymkiewicz, A., Sudheer, K.P., Nambi, I.M., 2018. Implementation of solute transport in the vadose zone into the 'HYDRUS package for MODFLOW'. Groundwater, (under review).

Deurer, M., Bachmann, J., 2007. Modeling water movement in heterogeneous water-repellent soil: 2. A conceptual 
numerical simulation. Vadose Zone Journal, 6, 446-457. DOI: $10.2136 /$ vzj2006.0061

Diamantopoulos, E., Durner, W., Reszkowska, A., Bachmann, J., 2013. Effect of soil water repellency on soil hydraulic properties estimated under dynamic conditions. Journal of Hydrology, 486, 175-186.

Hartmann, A., Šimůnek, J., Aidoo, M.K., Seidel, S.J., Lazarovitch, N., 2018. Modeling root growth as a function of different environmental stresses using HYDRUS. Vadose Zone Journal, 17, 16 p. DOI: 10.2136/vzj2017.02.0040.

Hlaváčiková, H., Novák, V., Šimůnek, J., 2016. The effects of rock fragment shapes and positions on modeled hydraulic conductivities of stony soils. Geoderma, 281, 39-48. DOI: 10.1016/j.geoderma.2016.06.034.

Jones, J.W., Hoogenboom, G., Porter, C.H., Boote, K.J., Batchelor, W.D., Hunt, L.A., Wilkens, P.W., Singh, U., Gijsman, A.J., Ritchie, J.T., 2003. DSSAT cropping system model. European Journal of Agronomy, 18, 235-265.

Langergraber, G., Šimůnek, J., 2012. Reactive transport modeling of subsurface flow constructed wetlands using the HYDRUS Wetland module. Vadose Zone Journal, 11, 2, 14 p. DOI: 10.2136/vzj2011.0104.

McDonald, M.G., Harbaugh, A.W., 2003. The history of MODFLOW. Ground Water, 41, 2, 280-283.

Novák, V., Kňava, K., Šimůnek, J., 2011. Determining the influence of stones on hydraulic conductivity of saturated soils using numerical method. Geoderma, 161, 3-4, 177181. DOI: 10.1016/j.geoderma.2010.12.016.

Parajuli, K., Sadeghi, M., Jones, S.B., 2017. A binary mixing model for characterizing stony-soil water retention. Agricultural and Forest Meteorology, 244-245, 1-8.

Parkhurst, D.L., Appelo, C.A.J., 2013. Description of input and examples for PHREEQC Version 3 - A computer program for speciation, batch-reaction, one-dimensional transport, and inverse geochemical calculations. Chapter 43 of Section A, Ground Water, Book 6, Modeling Techniques. U.S. Department of the Interior, U.S. Geological Survey, Reston, Virginia, 497 p.

Robinson, D.A., Lebron, I., Ryel, R.J., Jones, S.B., 2010. Soil water repellency, a method of soil moisture sequestration in Pinyon-Juniper woodland. Soil Science Society of America Journal, 74, 2, 624-634.

Scanlon, B.R., Christman, M., Reedy, R.C., Porro, I., Šimůnek, J., Flerchinger, G.F., 2002. Intercode comparisons for simulating water balance of surficial sediments in semiarid regions. Water Resources Research, 38, 12, 1323, 59.159.16. DOI: $10.1029 / 2001$ WR001233.

Schelle, H., Iden, S.C., Peters, A., Durner, W., 2010. Analysis of the agreement of soil hydraulic properties obtained from multistep-outflow and evaporation methods. Vadose Zone Journal, 9, 4, 1080-1091.

Schindler, J., Durner, W., von Unold, G., Müller, L., 2010. Evaporation method for measuring unsaturated hydraulic properties of soils: Extending the measurement range. Soil Science Society of America Journal, 74, 4, 1071-1083.

Šimůnek, J., 2005. Models of water flow and solute transport in the unsaturated zone. In: Anderson, M.G., McDonnell, J.J. (Eds): Encyclopedia of Hydrological Sciences, Chapter 78. John Wiley \& Sons, Ltd., Chichester, UK, pp. 1171-1180.

Šimůnek, J., Bradford, S.A., 2008. Vadose Zone Modeling: Introduction and importance. Vadose Zone Journal, 7, 2, 581-586. DOI: 10.2136/VZJ2008.0012.

Šimůnek, J., Wendroth, O., van Genuchten, M.T., 1998. Parameter estimation analysis of the evaporation method for determining soil hydraulic properties. Soil Science Society of America Journal, 62, 4, 894-905.

Šimůnek, J., van Genuchten, M.Th., Šejna, M., 2016. Recent developments and applications of the HYDRUS computer software packages. Vadose Zone Journal, 15, 7, 25 p. DOI: 10.2136/vzj2016.04.0033.

Steefel, C.I., Appelo, C.A.J., Arora, B., Jacques, D., Kalbacher, T., Kolditz, O., Lagneau, V., Lichtner, P.C., Mayer, K.U., Meeussen, J.C.L., Molins, S., Moulton, D., Shao, H., Šimůnek, J., Spycher, N., Yabusaki, S.B., Yeh, G.T., 2015. Reactive transport codes for subsurface environmental simulation. Computational Geosciences, 19, 3, 445-478. DOI: $10.1007 / \mathrm{s} 10596-014-9443-\mathrm{x}$.

Twarakavi, N.K.C., Šimůnek, J., Seo, H.S., 2008. Evaluating interactions between groundwater and vadose zone using HYDRUS-based flow package for MODFLOW. Vadose Zone Journal, 7, 2, 757-768.

Vereecken, H., Schnepf, A., Hopmans, J.W., Javaux, M., Or, D., Roose, T., Vanderborght, J., Young, M.H., Amelung, W., Aitkenhead, M., Allisson, S.D., Assouline, S., Baveye, P., Berli, M., Brüggemann, N., Finke, P., Flury, M., Geiser, T., Govers, G., Ghezzehei, T., Hallett, P., Hendricks Franssen, H.J., Heppel, J., Horn, R., Huisman, J.A., Jacques, D., Jonard, F., Kollet, S., Lafolie, F., Lamorski, K., Leitner, D., McBratney, A., Minasny, B., Montzka, C., Nowak, W., Pachepsky, Y., Padarian, J., Romano, N., Roth, K., Rothfuss, Y., Rowe, E.C., Schwen, A., Šimůnek, J., Titak, A., van Dam, J., van der Zee, S.E.A.T.M., Vogel, H.J., Vrugt, J.A., Wöhling, T., Young, I.M., 2016. Modeling soil processes: Review, key challenges, and new perspectives. Vadose Zone Journal, 15, 5, 57 p. DOI: 10.2136/vzj2015.09.0131 